\title{
EL APOYO INTERNACIONAL A LA REFORMA EDUCATIVA EN ESPAÑA ${ }^{\alpha}$
}

\section{International Support for Educational Reform in Spain}

\author{
Lorenzo Delgado Gómez-Escalonilla ${ }^{\beta}$ y Óscar J. Martín Garcíar
}

Fecha de recepción: 27/09/2020 • Fecha de aceptación: 20/01/2021

Resumen. En la década de los años sesenta se suscitó un debate internacional sobre el papel de la educación dentro de los cambios políticos, sociales y económicos que se estaban produciendo a nivel mundial. Organismos multilaterales como la OCDE y la UNESCO tuvieron un destacado papel en ese proceso, aplicando los planteamientos centrales de las teorías de la modernización y del capital humano para favorecer el tránsito desde «sociedades tradicionales» a otras más «modernas». Tales ideas tuvieron su traslación al escenario español de la mano de los «tecnócratas», que aspiraban a convertirse en los agentes de un proyecto de transformación controlado desde el aparato del Estado. Los organismos internacionales participaron activamente en el análisis del sistema educativo español, e hicieron recomendaciones sobre las medidas a tomar para ponerlo en sintonía con las necesidades económicas del país. El corolario de todo ello fue su apoyo a la reforma que condujo a la Ley General de Educación de 1970, que contó también con el soporte de algunos de los principales interlocutores exteriores del régimen franquista, como Estados Unidos, junto al Banco Mundial y la Fundación Ford. Dicho respaldo se plasmó en asesoramiento, financiación, formación de especialistas y

\footnotetext{
${ }^{\alpha}$ Este trabajo se ha realizado en el marco de los proyectos de investigación: Modernización, desarrollo y democratización. El papel de las potencias europeas occidentales y de las organizaciones internacionales en el cambio político y social en España (PGC2018-097159-B-I00), Los Agentes del Sistema Español de Innovación: Estrategias de aprendizaje y difusión del conocimiento durante la transición económica, 1959-1986 (PGC2018-098057-A-I00), y Asistencia exterior y modernización industrial y científico-técnica en Castilla-León: Análisis de potencialidades locales y opciones globales, c.1950-actualidad (SA241P18).

B Instituto de Historia, Centro de Ciencias Humanas y Sociales, Consejo Superior de Investigaciones Científicas. Albasanz, 26-28, 28037 Madrid, España. lorenzo.delgado@cchs.csic.es (D) https://orcid. org/0000-0001-6141-0810

$\gamma$ Departamento de Historia, Teorías y Geografía Políticas, Facultad de Ciencias Políticas y Sociología, Universidad Complutense de Madrid. Campus de Somosaguas. 28223 Pozuelo de Alarcón (Madrid), España. oscarjma@ucm.es
}

Cómo citar este artículo: Delgado Gómez-Escalonilla, Lorenzo y Óscar J. Martín García. «El apoyo internacional a la reforma educativa en España». Historia y Memoria de la Educación 14 (2021): 177-208 
material educativo. Esta contribución aborda la trayectoria de ese proceso, examinando la labor desempeñada por los actores internacionales y su implicación en la modernización educativa del país como paso hacia la convergencia con los parámetros del modelo occidental.

Palabras clave: España; siglo XX; educación y franquismo; organizaciones internacionales; reforma educativa; modernización.

Abstract. In the 1960s, an international debate emerged on the role of education in the worldwide changes taking place in the political, social and economic sphere. Multilateral agencies such as the OECD and UNESCO played an important role in this process. Inspired by some of the central tenets of modernization and human capital theories, these organizations sought to steer the transitions from "traditional societies" to "modern" ones. In Franco's Spain, this process of modernization was led by the technocratic sectors of the dictatorship, who aspired to become the agents of a project of change controlled from the state apparatus. International organizations actively participated in the analysis of the Spanish educational system, and recommendeding measures to bring it into line with the needs of economic development. The corollary of this work was their support for the 1970 General Education Law, which also enjoyed the endorsement of some of the main foreign allies of the Franco regime, such as the United States, the World Bank and the Ford Foundation. This support took the form of advice, funding, specialist training and educational assistance. The article addresses this whole process. It examines the efforts of various international actors and their involvement in the modernization of education in Spain as a step towards convergence with the Western model.

Keywords: Spain; 20th century; Francoism and education; international organizations; educational reform; modernization.

\section{INTRODUCCIÓN}

La Ley General de Educación (LGE) de 1970 representó, hasta cierto punto, la culminación de una serie de reformas educativas adoptadas en España a lo largo de los años sesenta. Si al concluir la guerra civil con el triunfo del bando franquista la enseñanza había tenido sus pilares ideológicos en la formación patriótica y religiosa, a partir de aquella década la adopción de una nueva política económica, destinada a incorporar al país a la estela expansiva del capitalismo occidental, propició también una reorientación en el plano educativo. Tras la puesta en marcha del Plan de Estabilización en 1959, España comenzó a experimentar cambios 
económicos y sociales sin precedentes. En apenas unos años el país se subió al tren del desarrollo, con el ascenso a la cúspide del poder de los denominados tecnócratas que aspiraban a encauzar el rumbo de la economía mediante el recurso a la planificación. ${ }^{1}$ En este nuevo escenario el papel de la enseñanza no podía ceñirse al ensalzamiento del pasado glorioso y su entronque con el régimen franquista. Más allá de la legitimación de la dictadura, que persistió, el aparato escolar debía asumir otra función esencial: la formación profesional y técnica del capital humano que habría de contribuir a la misión del desarrollo nacional. Como recogía un analista de la LGE a los pocos años de su promulgación: «La legislación de 1970 traduce este proceso de transformación y de adaptación de la escuela en esta nueva fase del capitalismo español».2

En el transcurso de aquella década, la fisonomía de España como país rural dejó paso a una progresiva concentración urbana, donde se ubicaban las empresas industriales y de servicios, provocando desplazamientos masivos de población del campo a la ciudad y del centro hacia la periferia del país. Los cambios en la estructura productiva y los movimientos demográficos propiciaron un paulatino incremento de las capas medias y de la clase obrera industrial en las zonas urbanas. En esos medios fueron cuajando nuevas expectativas de movilidad social directamente vinculadas con una mejor formación a través de la vía reglada del aparato escolar o por la informal del aprendizaje en el trabajo. ${ }^{3}$ Desde la óptica de los planificadores del desarrollo, la mejora de la capacitación de la mano de obra se convirtió igualmente en una prioridad, en tanto que incentivo para afianzar el crecimiento económico. La formación de capital humano parecía el punto de encuentro entre las necesidades productivas del desarrollo y las aspiraciones de ascenso social de amplias capas de la creciente población urbana.

Estos planteamientos subyacieron en las reformas educativas emprendidas por los cuadros tecnócratas de la dictadura durante los años

\footnotetext{
1 Joseba De la Torre y Mario García Zúñiga (eds.), Entre el mercado y el Estado. Los planes de desarrollo durante el franquismo (Pamplona: Universidad Pública de Navarra, 2009).

2 Alfonso C. Comín, «Educación 1938-70. De la ideología espiritualista a la ideología tecnocrática», Cuadernos para el Diálogo, extra XXXVII (1973): 350.

3 Javier Echeverría Zabalza, La movilidad social en España (1940-1991) (Madrid: Itsmo, 1999), 363365.
} 
sesenta. No fue ni mucho menos una singularidad hispana, sino una de tantas experiencias en una década caracterizada por una expansión cuantitativa de los sistemas educativos en muchos países en vías de desarrollo. ${ }^{4}$ A esa tarea prestaron su respaldo y asesoramiento las organizaciones internacionales, cuya cooperación representó un elemento esencial en el camino que llevó a la Ley de 1970. Sin embargo, las previsiones tanto de los expertos internacionales que proporcionaron su asistencia técnica, como de los equipos de planificadores españoles que las trasladaron fragmentariamente a sus planes de acción, distaron de acompasarse con la realidad. El desajuste provocado por el tardío y limitado grado de cumplimiento de tales recomendaciones, acorde con la insuficiencia de los recursos destinados a ello, impidió una aplicación eficiente de las reformas educativas realizadas durante este período, incluyendo la LGE.

\section{ANTECEDENTES DE LA ASISTENCIA EXTERIOR: ESPAÑA, UN DISCÍPULO INDOLENTE}

Al igual que ocurriera con el cambio de política económica emprendido en 1959, los organismos internacionales respaldaron el giro de timón de la política educativa asumido por los cuadros tecnócratas algo después. En el terreno económico, los dirigentes tecnócratas contaron con el asesoramiento y la financiación proporcionados por el Fondo Monetario Internacional (FMI), el Banco Mundial (BM) y la Organización Europea de Cooperación Económica (OECE, luego Organización para la Cooperación y el Desarrollo Económico-OCDE), además del apoyo de Estados Unidos. ${ }^{5}$ En la elaboración de sus recetas económicas adaptaron al caso español los presupuestos de la teoría de la modernización americana y la planificación indicativa francesa, con el propósito de

\footnotetext{
${ }^{4}$ John W. Meyer, Francisco Ramírez, Richard Robinson and John Boli-Bennet, «The World Educational Revolution, 1950-1970», en National Development and the World System: Educational, Economic, and Political Change, 1950-1970, eds. John W. Meyer and Michael T. Hannan (Chicago: University of Chicago Press, 1979), 37-56; Robert Fiala and Audri Gordon Lanford, «Educational Ideology and the World Education Revolution, 1950-1970», Comparative Education Review 31/3 (1987): 315333.

5 Joaquim Muns y Montserrat Millet, España y el Banco Mundial. Relaciones 1958-1994 (Madrid: Mundi Prensa, 1994); Lorenzo Delgado Gómez-Escalonilla, «El ingreso de España en la Organización Europea de Cooperación Económica», Arbor 669 (2001): 147-179; Elena Cavalieri, España y el FMI: la integración de la economía española en el sistema monetario internacional, 1943-1959 (Madrid: Banco de España, 2014).
} 
llevar a cabo una transformación desde dentro y bajo control del Estado franquista. Conscientes del progresivo deterioro de las bases de sustentación ideológica del régimen, los tecnócratas creyeron necesario dotar de una nueva legitimación al franquismo en un contexto en el que los réditos de la victoria de la guerra civil se iban diluyendo en el tiempo, y solo la represión conseguía acallar las voces contestatarias que empezaban a surgir sobre todo en el mundo laboral y universitario.

La fórmula empleada fue la de promover reformas «desde arriba» alentadas «desde fuera», con el desarrollo económico y la modernización como metas, y con la planificación como principal instrumento prospectivo. El fin último era asegurar la continuidad del régimen, procurando mediante la planificación del desarrollo encauzar las expectativas de mejora en las condiciones de vida que se iban extendiendo entre la sociedad española. Desde esta óptica, se hacía imprescindible poner la educación al servicio del crecimiento económico que, a su vez, promovería el bienestar social, reduciría el conflicto de clases y aseguraría la pervivencia de la dictadura ante «el shock del futuro». ${ }^{6}$

Tanto en el campo económico como en el educativo, los tecnócratas actuaron como interlocutores privilegiados con el exterior e intérpretes a escala local de las recomendaciones emanadas de las organizaciones internacionales de referencia. De esa capacidad para obtener la colaboración externa, y a menudo los créditos que aparejaba, extraían una parte no desdeñable de la influencia para sacar adelante sus propuestas en el núcleo de poder del franquismo. Carentes de arraigo social y de una base de apoyo con la que sí contaban otras «familias» del régimen, los tecnócratas se amparaban en su competencia profesional y su capacidad de gestión, más moderna y receptiva hacia la evolución del mundo occidental. Su método de acción, pues, fue estrechar contactos con las organizaciones internacionales, manifestar su disposición a trasladar sus propuestas a una reforma paulatina del sistema educativo, y erigirse también en este ámbito en los adalides del «cambio planificado».

\footnotetext{
6 José Jiménez Blanco, «Desarrollo económico-Democracia política», en España perspectiva 1972 (Madrid: Guadiana de Publicaciones, 1972), 161. Ese texto indagaba también, con acierto, en la lectura que hacían los tecnócratas españoles de la teoría de la modernización, para cuestionar la supuesta deriva del desarrollo económico hacia la democracia política.
} 
Desde el ingreso en la United Nations Educational, Scientific and Cultural Organization (UNESCO) en 1953, y más tarde en la OECE en 1959, España accedió a los circuitos de información sobre ideas y métodos pedagógicos, modelos y prácticas docentes, que componían lo que se ha denominado como global architecture of education. ${ }^{7}$ Durante los años sesenta dicha arquitectura trasnacional pretendió ofrecer respuestas a los desafíos planteados por la descolonización, las crecientes expectativas de cambio social en los países en vías de desarrollo y el ascenso de los movimientos revolucionarios en el Tercer Mundo. Para ello propusieron y difundieron un esquema de desarrollo que guiaría a dichos países por el «camino correcto» hacia el progreso, librándoles del caos político y social. ${ }^{8}$ La UNES$\mathrm{CO}$, la OCDE y más adelante el BM pusieron en el centro de sus preocupaciones y ocupaciones la «modernización ordenada» del Global South, como antídoto contra la pobreza y la inestabilidad política. Además de mejorar las condiciones de instrucción y de vida de la población de aquellos territorios, dicha labor tenía como cometido implícito sustraerles de caer en la órbita comunista. Es decir, sus motivaciones no fueron ajenas a las estrategias desplegadas en el contexto de la Guerra Fría. ${ }^{9}$

La singladura española en esos circuitos se inició con la presencia de funcionarios de alto nivel en algunos de los foros donde se gestaban y difundían las nuevas «semánticas de modernización».10 Por esa vía se estrecharon vínculos con expertos internacionales y se conocieron las experiencias promovidas por la UNESCO y la Organización de Estados Americanos (OEA) para impulsar la enseñanza primaria en América Latina, asociadas a lo que entonces se llamaba planeamiento integral de la educación. ${ }^{11}$

\footnotetext{
7 Phillip W. Jones, Education, Poverty and the World Bank (New York: Sense Publishers, 2006), 48-49.

${ }^{8}$ Michel E. Latham, The Right Kind of Revolution: Modernization and US Foreign Policy from the Cold War to the Present (Ithaca, NY: Cornell University Press, 2012).

${ }_{9}$ David Engerman et al. (eds.), Staging Growth: Modernization, Development and the Global Cold War (Boston: University of Massachusetts Press, 2003); David C. Engerman, «The Romance of Economic Development and New Histories of the Cold War», Diplomatic History 28/2 (2004): 23-55; Charles Dorn and Kristen Ghodsee, «The Cold War Politicization of Literacy: Communism, UNESCO, and the World Bank», Diplomatic History 36/2 (2012): 373-398.

10 Jürgen Schriewer, «Sistema mundial y redes de interrelación: la internacionalización de la educación y el papel de la investigación comparada», Educación y Ciencia 1/15 (1997): 28.

${ }_{11}$ Principios de planeamiento (Washington: UNESCO, 1960); Gabriel Betancourt Mejía, Documentos para la historia del planeamiento integral de la educación (Bogotá: Universidad Pedagógica Nacional, 1984); Alberto Martínez Boom, De la escuela expansiva a la escuela competitiva. Dos modos de modernización educativa en América Latina (Barcelona: Anthropos, 2004), 91 y ss.; Gabriela Ossenbach and
} 
También comenzaron a llegar a las revistas españolas especializadas las premisas positivistas y funcionalistas que pretendían modernizar los procesos de enseñanza y aprendizaje, en materias como la enseñanza programada, las campañas de alfabetización, la revisión de manuales escolares o la formación de los docentes. ${ }^{12}$

Los principales escollos para la aplicación al sistema educativo español de aquellos contenidos y métodos renovadores derivaban de su fuerte carácter clasista, que impedía a las capas sociales menos pudientes acceder a estudios medios y superiores; de la escasez de recursos presupuestarios, materiales y humanos; junto a la influencia de una Iglesia católica, garante de los valores del régimen, que con su control de la enseñanza media filtraba el acceso a los niveles más altos de instrucción. En la segunda mitad de los años cincuenta se comenzaron a afrontar las serias deficiencias existentes en materia de instalaciones de enseñanza primaria (falta de aulas) y de centros de formación técnica. El resultado fue una ampliación del radio de acción en la primera y la creación de Escuelas Técnicas Superiores y de Grado Medio con nuevos planes de estudio y mejores equipos e instalaciones. En ambos casos se trató de medidas imprescindibles, pero acometidas con medios insuficientes. ${ }^{13}$

Hubo que esperar a los años sesenta para que los proyectos reformistas en el campo de la enseñanza comenzasen a adquirir mayor relevancia, ahora dentro de los proyectos tecnócratas, con las miras puestas en mejorar las capacidades productivas del país y acompasarlas con el ritmo del cambio social. ${ }^{14}$ Para sustentar el crecimiento se necesitaban profesionales y técnicos capacitados, cuya formación correspondía al

\footnotetext{
Alberto Martínez Boom, «Itineraries of the Discourses on Development and Education in Spain and Latin America (circa 1950-1970)», Paedagogica Historica 47/5 (2011): 679-700; Óscar J. Martín García and Lorenzo Delgado Gómez-Escalonilla (eds.), Teaching Modernization. Spanish and Latin American Educational Reform in the Cold War (New York: Berghahn Books, 2020).

12 Mariano González-Delgado y Tamar Groves, «La enseñanza programada, la UNESCO y los intentos por modificar el currículum en la España desarrollista (1962-1974)», Espacio, Tiempo y Educación 4/2 (2017): 73-100, y «Educational Transfer and Local Actors: International Intervention in Spain during the Late Franco Period», en Teaching Modernization, ed. Martín y Delgado, 101-126.

${ }_{13}$ Emilio Lázaro Flores, «Historia de las construcciones escolares en España», Revista de Educación 240 (1975): 119-121; Gregorio Millán Barbany y Carlos Sánchez Tarifa, «Las enseñanzas técnicas en España», Anales de Moral Social y Económica (1964): 159-168.

${ }^{14}$ Lorenzo Delgado Gómez-Escalonilla, «International Organizations and Educational Change in Spain during the Sixties», Encounters in Theory and History of Education 21 (2020): 70-91.
} 
sistema educativo. Al igual que sucedía con la economía, la enseñanza debía incorporarse a la planificación del desarrollo. La cooperación con la OCDE y la UNESCO aportó experiencias y modelos que sirvieron como guía orientadora de las medidas a tomar, sumando a los especialistas españoles al debate abierto por medios intelectuales y pedagógicos europeos y americanos. ${ }^{15}$ Otra cuestión diferente fue su impacto real.

La situación de partida dejaba mucho que desear. A principios de los años sesenta, la instrucción general de la mano de obra era muy baja. El $9 \%$ de la población activa carecía de estudios y en torno al $85 \%$ solo había superado la enseñanza primaria. La escasa calidad de la formación recibida en ese nivel empeoraba dicho escenario. Tampoco los sectores minoritarios que accedían a la enseñanza secundaria, con fuerte implantación de los centros religiosos, recibían un aprendizaje satisfactorio, a juicio de la OCDE, que extendía su dictamen negativo a la formación profesional y el bachillerato laboral (ambos con una audiencia aún más reducida). No salía mejor parada de ese diagnóstico la enseñanza universitaria, cuyo rendimiento también se consideraba bajo y con disciplinas tradicionales como Derecho y Medicina todavía con elevada demanda, en tanto que los estudiantes de materias científicas y técnicas solo aumentaban muy lentamente. Algo mejor paradas salían las escuelas técnicas y las facultades de Ingeniería (en particular la especialidad de Industriales). El cuadro lo completaban una menor presencia de las mujeres en el ciclo formativo, que disminuía además conforme se pasaba a los niveles superiores; la precariedad de un colectivo docente no siempre bien formado y en su conjunto mal pagado, por lo que debía compaginar su labor con otras ocupaciones y, como colofón, una elevada tasa de abandono escolar. ${ }^{16}$

Ese sombrío panorama se asemejaba en muchas de sus variables al de otros países europeos de la cuenca mediterránea, cuyos sistemas educativos elitistas entorpecían la modernización de su aparato productivo. ${ }^{17}$

\footnotetext{
15 Agustín Escolano Benito, «Discurso ideológico, modernización técnica y pedagogía crítica durante el franquismo», Historia de la Educación 8 (1989): 12.

${ }^{16}$ Las necesidades de educación y el desarrollo económico-social de España (Madrid: MEN-OCDE, 1963); The Mediterranean Regional Project. Spain (OECD: Paris, 1965); Salustiano del Campo, Cambios sociales y formas de vida (Barcelona: Ariel, 1968), 200-217.

${ }^{17}$ Ese conjunto de países agrupaba a Italia, Grecia, Portugal, Turquía, Yugoslavia y España. «The Mediterranean Regional Project», The OECD Observer 8 (1964): 1-12.
} 
Ante tal desafío, la OCDE puso en marcha en 1961 el Proyecto Regional Mediterráneo (PRM), que aspiraba a sincronizar las capacidades formativas con las demandas del desarrollo económico. España se integró a finales de ese año en el PRM, nombrándose como responsable de coordinar el equipo español a Joaquín Tena Artigas, director general de Enseñanza Primaria del Ministerio de Educación Nacional español (MEN).18 Ese equipo llevó a cabo una labor sistemática de recopilación de datos sobre el panorama educativo español, enfrentándose a notables insuficiencias en la información de algunas fuentes, sobre todo los centros escolares privados. Con la asistencia de la OCDE, sus análisis ayudaron a tomar conciencia del lamentable estado del sistema educativo español, además de perfilar las medidas que podían aplicarse para generar el capital humano necesario para el desarrollo económico del país. ${ }^{19}$ En tal sentido, España tenía que actuar con celeridad si quería recuperar el tiempo perdido en las últimas décadas.

La voluntad de afrontar el reto de la modernización educativa se escenificó en un curso-coloquio sobre Planeamiento integral de la educación, celebrado en Madrid en junio de 1962 con la colaboración de la UNESCO. El impulsor de aquellas jornadas fue precisamente Tena Artigas, y su principal interlocutor en la citada organización internacional fue Ricardo Díez Hochleitner. En sus sesiones se abordó la ampliación de la edad de escolarización obligatoria, la selección y el perfeccionamiento del profesorado, la revisión de los planes de estudio, la renovación de los edificios y materiales escolares, la orientación profesional y la extensión cultural, la enseñanza de idiomas o la educación de las mujeres. También se avanzó que el horizonte para 1970 era incrementar la inversión en educación al menos hasta el 4,04\% de la renta nacional y crear 2.571.000 nuevos puestos escolares (más de la mitad en enseñanza media ${ }^{20}$. La planificación integral de la enseñanza habría de coordinarse durante los próximos años con los planes de desarrollo económico que

\footnotetext{
18 Tena Artigas actuó como interlocutor español con la UNESCO en materia educativa hasta los años 70, formando parte asimismo de la Comisión Nacional de enlace con esa organización. CV Joaquín Tena Artigas, octubre-1977. Archivo General de la Universidad de Navarra (AGUN), Fondo Joaquín Tena Artigas, 300.

${ }^{19}$ Lorenzo Delgado Gómez-Escalonilla, «Educación para el desarrollo. OCDE, asistencia exterior y reforma de la enseñanza en la España del tardofranquismo», Foro de Educación 18/2 (2020): 127-148.

${ }^{20}$ La educación y el desarrollo económico-social. Planeamiento integral de la educación. Objetivos de España para 1970 (Madrid: MEN, 1962), 181-187 y 199-201.
} 
por entonces se iniciaban. Era una muestra del ascendiente que cobraron en aquellos años los "planificadores de la educación»" en paralelo a sus colegas del ámbito económico.

Con tal objetivo, aquel mismo año se colocó al frente del MEN a Manuel Lora Tamayo, investigador ligado al Consejo Superior de Investigaciones Científicas (CSIC) y de perfil tecnócrata, con buenas conexiones exteriores. Bajo su mandato se elevó la escolaridad obligatoria a los 14 años y se promulgó la Ley de Educación Primaria, se tomaron más medidas para incentivar las enseñanzas técnicas sobre todo a través de las Escuelas de Ingeniería y de Peritos, y se buscó dinamizar la enseñanza media y los estudios superiores, estos últimos con una Ley de Enseñanza Universitaria. Aquellas iniciativas pretendían remover estructuras arcaicas e insuflar aires renovadores en el entramado docente, algo que se apreció asimismo en los Cuestionarios Nacionales de Enseñanza de 1965 que incorporaban métodos didácticos y concepciones organizativas más en línea con las recomendaciones de la UNESCO.22 Otra iniciativa promovida en aquellos años estuvo encaminada a disponer de un mayor número de especialistas en gestión educativa, iniciándose en 1966 unos cursos de Administración y Planificación de la Educación en el Centro de Formación y Perfeccionamiento de Funcionarios, bajo la dirección de José M. Paredes Grosso. Aquel fue un vivero del que saldrían bastantes cuadros comprometidos con la reforma educativa unos años más tarde. ${ }^{23}$

Por otro lado, los docentes españoles comenzaron a familiarizarse con materias como la graduación, las unidades didácticas, la evaluación, el control del rendimiento, el uso de pruebas objetivas o la utilización de medios audiovisuales, al menos por el eco que muchas de esas cuestiones encontraban en las revistas especializadas de su ámbito. ${ }^{24}$ También comenzó a disponer de mayor audiencia el aprendizaje del inglés,

${ }_{21}$ José L. Romero, «Del Libro Blanco a la Ley General de Educación», en España Perspectiva 1971, (Madrid: Guadiana de Publicaciones, 1971), 219.

${ }_{22}$ Antonio Viñao, Escuela para todos. Educación y modernidad en la España del siglo XX (Madrid: Marcial Pons, 2004), 69-80.

${ }^{23}$ Romero, «Del Libro Blanco», en España Perspectiva 1971, 219.

24 Viñao, Escuela para todos, 74-75; González-Delgado y Groves, «La enseñanza programada»; David Corrales Morales, "Ciudadanos del mañana». La influencia estadounidense en la infancia durante el franquismo, 1953-75 (tesis doctoral, Universidad Complutense, 2019), 331-364; Mariano 
que ganaba espacio en las escuelas técnicas y las facultades de ciencias, e incluso como lengua optativa en la enseñanza secundaria. ${ }^{25}$ Todo aquel despliegue tenía como metas la ampliación de la audiencia de la población escolarizada y la mejora de la instrucción en todos los niveles, la actualización de la formación del profesorado y la introducción de métodos de aprendizaje más experimentales.

Al concluir la década, la enseñanza primaria alcanzó a la casi totalidad de la población escolar de esa franja de edad; la secundaria había triplicado prácticamente su alcance; la formación técnica y profesional aumentó más del doble sus matriculados, y las carreras universitarias de ciencia y tecnología registraron avances entre sus diplomados. Incluso la participación femenina ascendió en todos los niveles. Sin embargo, esos avances reflejaban todavía más una tendencia que una realidad consolidada. Hacían falta más recursos para asegurar la escolaridad obligatoria y la enseñanza secundaria se mantenía como una barrera infranqueable para muchas familias, que no disponían de medios para que sus hijos accediesen a esos estudios. En la universidad no se estaba mitigando la estratificación social, sino que se reforzaba. ${ }^{26}$ Las estimaciones y recomendaciones formuladas en los informes del PRM de la OCDE tampoco se habían cumplido. Las asignaciones financieras previstas en los planes de desarrollo habían sido inferiores a las sugeridas por aquellos estudios, a lo que se añadía que su grado de cumplimiento era todavía más bajo. La pretensión de que la educación fuese un factor de respaldo del desarrollo económico no se llevaba a la práctica ni en las proporciones ni al ritmo aconsejados. ${ }^{27}$ La expansión económica se sustentaba en buena medida en la dependencia del exterior, por la vía de la importación masiva de tecnología extranjera y por el establecimiento de

\footnotetext{
González-Delgado, "Estar a la altura de nuestro tiempo": la televisión educativa, la UNESCO y la modernización de la enseñanza en el franquismo», Hispania 265 (2020): 597-627.

25 Óscar J. Martín García y Francisco J. Rodríguez Jiménez, «¿Seducidos por el inglés? Diplomacia pública angloamericana y difusión de la lengua inglesa en España, 1959-1975», Historia y Política 29 (2013): 301-330.

${ }^{26}$ Campo, Cambios sociales, 230-245.

27 Las necesidades de graduados en España en el período 1964-1971 (Enseñanzas Media y Superior) (Madrid: Dirección General de Promoción y Cooperación Científica, 1966); Formation et fonctions des techniciens. Espagne (Paris: OCDE, 1968); Examen du developpment de l'enseignement dans les pays mediterranéens: Tendances et perspectives de l'enseignement dans les pays membres en voie de development (Paris: OECD, 1972).
} 
filiales de empresas de otros países, mucho más que por la capacidad de innovación interior favorecida por una disponibilidad creciente del capital humano bien formado. Tampoco se estaba respondiendo a las expectativas de promoción social a través de la oferta escolar, que reclamaban capas sociales cada vez más numerosas.

Los intentos de dinamizar el sistema educativo se producían con mayor lentitud y menor intensidad de lo que aconsejaban las organizaciones internacionales, o de lo que demandaban los cambios económicos, sociales y culturales que vivía el país. Las actuaciones emprendidas habían sido inconexas y llegaron a menudo con cuentagotas a los centros de enseñanza. La ideología espiritualista y autoritaria mantenía su impronta sobre el sistema escolar, pese a los retoques en los planes de estudios y programas. A lo que se sumaban las resistencias existentes entre los potenciales implicados en el cuerpo docente. Unos porque eran reacios a asumir innovaciones que requerían una actualización de sus conocimientos y una mayor carga de trabajo. Otros porque no se sentían partícipes de aquellas medidas adoptadas sin contar con sus opiniones y que, además, no se traducían en una mejora de sus condiciones laborales. Los más porque no apreciaban que el discurso reformista esgrimido ante la opinión pública, y que se amparaba en el concurso de las organizaciones internacionales, franquease el umbral de las aulas. ${ }^{28}$

La distancia entre los supuestos postulados reformistas de los dirigentes del régimen franquista y las demandas de una sociedad en mutación se hizo cada vez más evidente. A los prebostes de la dictadura les costaba asimilar la celeridad de la irrupción de las clases medias, los efectos de la sociedad de consumo sobre la transformación de las mentalidades y los hábitos de conducta en los entornos urbanos, la secularización en ascenso, o la renovada conciencia de clase que prendía en el proletariado industrial. En los campus universitarios las protestas estudiantiles se intensificaron por la falta de canales de representación y la deficiente calidad de una enseñanza cada vez más masificada. Allí se produjo la mayor fisura, ya que los conatos de revuelta se asociaban con

\footnotetext{
${ }_{28}$ Cecilia C. Milito Barone y Tamar Groves, «¿Modernización o democratización? La construcción de un nuevo sistema educativo entre el tardofranquismo y la democracia», Bordón 65/4 (2013): 135148; González-Delgado y Groves, «Educational Transfer».
} 
el cuestionamiento de la propia dictadura. ${ }^{29}$ Incapaz de atajar esa explosiva situación, Lora Tamayo presentó su dimisión.

\section{LA BÚSQUEDA DEL AVAL INTERNACIONAL PARA LA REFORMA EDUCATIVA}

En abril de 1968 fue nombrado ministro de Educación José Luis Villar Palasí, un catedrático de universidad vinculado a los sectores tecnócratas de la dictadura, que impulsaría la aprobación de la LGE en agosto de $1970 .{ }^{30}$ En principio el nuevo ministro identificó como su campo preferente de acción la universidad, con las miras puestas en desactivar la creciente revuelta estudiantil. Pero pronto cambió su perspectiva y empezó a considerar los problemas universitarios como la punta del iceberg: el conjunto del sistema educativo requería una profunda modificación. ${ }^{31}$ Posiblemente a ello contribuyeron los consejos provenientes de las organizaciones internacionales, que habían animado y, hasta cierto punto, supervisado los proyectos previos de modernización educativa. Ante el limitado alcance del proceso de reformas puntuales de la década anterior se decantaban por una operación de mayor calado. En el otoño de 1968 una misión conjunta de la UNESCO, el BM y la Organización de las Naciones Unidas para la Alimentación y la Agricultura (FAO) visitó España para evaluar el estado de sus estructuras educativas. Como conclusión fundamental de su informe se propugnaba «un cambio radical» en el sistema escolar español mediante un "plan general educativo a largo plazo».32

Las autoridades españolas atendieron tal recomendación, con la puesta en marcha de un ambicioso proyecto de reforma educativa que

\footnotetext{
29 Elena Hernández Sandoica, Miguel A. Ruiz Carnicer y Marc Baldó Lacomba, Estudiantes contra Franco (1939-1975). Oposición política y movilización juvenil (Madrid: La Esfera de los Libros, 2007), 265-275.

30 Viñao, Escuela para todos, 80-82.

31 Manuel Puelles Benítez, «Tecnocracia y política en la reforma educativa de 1970», Revista de Educación n. ${ }^{\circ}$ ext. «La Ley General de Educación veinte años después» (1992): 18.

32 «España. La Reforma de la Educación. Informe Preliminar (Confidencial EFM/17)», febrero-1969. UNESCO Archive (UA), caja UIL 370.51 Sp ARCHIV. Ver también Mariano González-Delgado y Tamar Groves, «UNESCO mediation in Francoist curriculum policy: The case of educational television in Spain», en Transnational Perspectives on Curriculum History, eds. Gary McCulloch, Ivor Goodson y Mariano González-Delgado (London: Routledge, 2020), 83-107.
} 
culminó con la promulgación de la mencionada LGE. ${ }^{33}$ Su cerebro y principal muñidor fue el secretario general técnico del Ministerio de Educación y Ciencia (MEC), Ricardo Díez Hochleitner, previamente director del Departamento de Planificación y Financiación de la UNESCO. Díez Hochleitner tenía una dilatada trayectoria profesional como experto en planeamiento y educación, junto a una agenda de estrechos contactos con múltiples organismos, instituciones y especialistas a nivel internacional. En los años cincuenta había sido asesor en temas educativos de la OEA y del Ministerio de Educación Nacional de Colombia. A principios de la década siguiente dirigió el «Plan decenal de educación para América Latina», como parte de la Alianza para el Progreso impulsada por la administración Kennedy, y posteriormente asumió en 1963 la dirección del Departamento de Inversiones en Educación del BM. Para llevar a cabo la profunda transformación en ciernes del sistema educativo, Díez Hochleitner se rodeó de un equipo de técnicos, no de políticos, que como era su caso aportaban una contrastada capacidad de trabajo e innovación. Igualmente importante era el hecho de que estos técnicos disponían de una amplia experiencia en las relaciones con las organizaciones internacionales, especialmente con la UNESCO. En ese grupo se integraban, entre otros, José Blat Jimeno, Joaquín Tena Artigas, José M. Paredes Grosso, Arturo de la Orden y Ángel Oliveros. ${ }^{34}$

No fue casual, pues, que el plan de reforma educativa en España recibiera un importante respaldo por parte de los principales actores exteriores en este campo. Tal fue el caso de uno de los proyectos estrella de dicha reforma, la creación en 1969 del Centro Nacional de Investigaciones para el Desarrollo de la Educación (CENIDE) y de los Institutos de Ciencias de la Educación (ICEs). La puesta en marcha de estos organismos (encargados de la formación del profesorado, de la promoción de la investigación educativa, del fomento de la innovación pedagógica y del desarrollo del

\footnotetext{
${ }^{33}$ Los gobernantes españoles, como se ha señalado previamente, solieron aceptar aquellas recomendaciones internacionales basadas en concepciones educativas tecnocráticas, en tanto que eran compatibles con la orientación ideológica del régimen franquista y sus objetivos de legitimación política a través del desarrollo. Juan M. Fernández Soria, «Presentación. Influencias europeas en la política educativa española del siglo XX (presencias y ausencias, temas para la investigación histórico-educativa)», Historia de la Educación 24 (2005): 31.

34 Ricardo Díez Hochleitner, «La reforma educativa de la LGE de 1970. Datos para una crónica», Revista de Educación n. ${ }^{\circ}$ ext. «La Ley General de Educación veinte años después» (1992): 264; Puelles, «Tecnocracia y política»: 19.
} 
currículum) contó con la asistencia técnica y económica de la UNESCO, del BM, del Programa de las Naciones Unidas para el Desarrollo (PNUD) y de la Fundación Ford. ${ }^{35}$ Esta fundación filantrópica y el PNUD aportaron sumas de 400.000 y 1.227.838 dólares, respectivamente, para financiar el trabajo de consultores externos y dotar de recursos a un programa de becas para educadores del CENIDE y de los ICEs. Esa financiación cubrió los gastos de quienes visitaron Estados Unidos y varios países europeos con el propósito de conocer de primera mano sus experiencias pedagógicas y sus estructuras docentes. Por su parte, la UNESCO y la OCDE promovieron misiones de expertos nacionales e internacionales que asesoraron a la red CENIDE-ICEs. Como veremos más adelante, el BM también prestó asistencia económica para esos centros de investigación educativa y financió la formación del personal docente e investigador. ${ }^{36}$

En resumidas cuentas, la ayuda internacional permitió al CENIDE: (1) impulsar entre 1970 y 1975 un amplio programa de becas de formación en el extranjero dirigido a la mejora de la docencia y la investigación en esferas como las de la televisión educativa, la enseñanza programada y la enseñanza asistida por ordenador, entre otras; (2) invitar a consultores extranjeros de reconocido prestigio en diversos campos educativos, como Michel Lobrot, George Bereday, Henry H. Levin y Robert F. Arnove; (3) adquirir equipamientos técnicos -circuito cerrado de televisión y equipos de enseñanza asistida por ordenador- necesarios para potenciar la investigación educativa; y (4) organizar conferencias y seminarios sobre temas vinculados a la reforma educativa, como el Seminario internacional de la UNESCO sobre el uso de modelos matemáticos en la planificación de la educación. ${ }^{37}$

De forma casi paralela a la fundación del CENIDE, la UNESCO facilitó recursos para realizar seminarios, grupos de trabajo, talleres de

\footnotetext{
35 Escolano, «Discurso ideológico»: 15-16; Francisco Rodríguez Jiménez, «Forerunners of Change? The Ford Foundation's Activities in Francoist Spain», en Teaching Modernization, ed. Martín y Delgado, 78-100.

36 Corrales, «Ciudadanos del mañana», 396-411.

37 "Asistencia al CENIDE, Madrid. (Proyecto SPANED-19). Informe de la Misión de Inspección», septiembre-1972; «Seminario internacional de la UNESCO sobre el uso de modelos matemáticos en la planificación de la educación», junio-1970. Archivo de la Comisión Nacional Española de Cooperación con la UNESCO (ACNEC-UNESCO), caja 75/Carpetilla 1 y caja 325/Carpetilla 2, respectivamente. Ver también González-Delgado y Groves, «La enseñanza programada» y González-Delgado, «Estar a la altura de nuestro tiempo».
} 
formación de personal y proyectos experimentales. ${ }^{38}$ Además, constituyó un comité de expertos en educación, sociología, psicología y economía, que se ocuparía de asesorar al MEC. En el denominado Comité de Cooperación Internacional para la Reforma Educativa en España participaron especialistas de alto nivel de la UNESCO, entre los que destacaban Gabriel Betancur (antiguo ministro de Educación en Colombia), Philip H. Coombs (que había sido Assistant Secretary of State for Education and Culture de la administración Kennedy y director del Instituto Internacional de Planeamiento Educativo de la UNESCO), y John Vaizey (economista especialista en educación, técnico de la UNESCO, profesor de Brunel University y autor de varios trabajos sobre educación y desarrollo). Su composición incluyó asimismo a un destacado plantel de cuadros de otras reputadas instituciones educativas internacionales.

La labor del comité consistió en realizar un análisis de algunas cuestiones fundamentales del proyecto previo a la ley (el conocido como $\mathrm{Li}$ bro Blanco ${ }^{39}$ ) y emitir sugerencias para mejorarlo. A este respecto, una de las áreas en que se resaltaba la utilidad de la cooperación internacional era la innovación educativa, faceta a la que como se ha indicado se consagró en principio la red CENIDE-ICEs. También se llamaba a promover «amplios programas de intercambio de profesores de todos los niveles con otros países», una recomendación que como veremos seguidamente trató de aplicarse en la medida de lo posible. Menor fortuna tuvo la advertencia sobre la «vital importancia de contar con la adhesión y colaboración entusiasta de los educadores», algo que estuvo lejos de lograrse ya que el colectivo docente quedó al margen de la elaboración de aquel proyecto y las condiciones de la posterior aplicación de la ley tampoco favorecieron su respaldo. Junto a lo anterior, uno de los objetivos implícitos de la actuación del comité fue dotar de reconocimiento exterior a los planteamientos de la reforma educativa, presentándola como una iniciativa "neutral y modernizadora», a lo que obviamente contribuía el perfil del equipo de tecnócratas españoles que la diseñaron. No era esta una dimensión menor para un régimen autoritario, que deseaba reforzar su legitimidad y rebajar la presión que ejercían en su contra los movimientos estudiantiles. En tal sentido, no dejaban de ser

\footnotetext{
${ }^{38}$ Díez, «La reforma educativa»: 272.

${ }^{39}$ La educación en España. Bases para una política educativa (Madrid: MEC, 1969).
} 
paradójicas, y en cierto grado proféticas, algunas afirmaciones contenidas en el informe final del comité, en particular cuando se hacía referencia al "gran desafío pedagógico implicado en la transformación de un sistema educativo tradicional, concebido originalmente para satisfacer las necesidades de una minoría privilegiada, en un sistema moderno y democrático que debe servir a la gran mayoría del país». ${ }^{40}$ Aseveraciones de esa índole, sin duda debían incomodar a más de un acólito de la dictadura, como pudo apreciarse cuando la ley pasó por el trámite de su aprobación en las Cortes franquistas.

Al hablar del respaldo exterior al cambio educativo en España también cabe mencionar la asistencia prestada por gobiernos como el de Gran Bretaña en ámbitos como la enseñanza del inglés, la investigación educativa y la creación en 1973 de la Universidad Nacional de Educación a Distancia (inspirada en parte en la Open University británica). ${ }^{41}$ Pero sin duda el gobierno occidental que tuvo un mayor protagonismo en la reforma educativa fue el de Estados Unidos. En 1969 la Administración estadounidense accedió a la solicitud española de facilitar asistencia educativa como una de las contrapartidas incluidas en la renovación de los acuerdos militares entre ambos países. A comienzos de ese año las negociaciones habían quedado en punto muerto, dada la renuencia estadounidense a aceptar las pretensiones españolas de reequilibrar la alianza estratégica. ${ }^{42}$ Para desatascar la situación, la parte española, a petición del ministro Villar Palasí a su colega de Asuntos Exteriores, sugirió atenuar las discrepancias en materia defensiva mediante la extensión de dichos convenios a otras áreas no militares de las relaciones bilaterales. ${ }^{43}$

40 «Comité de Cooperación Internacional para la reforma educativa en España. Informe final», 1970. Centro Documental de la Memoria Histórica-Archivo Fundación Nacional Francisco Franco (CDMH-AFNFF), doc. 974.

${ }^{41}$ Óscar J. Martín García, «La política exterior cultural del Reino Unido, el British Council y el final de la dictadura en España», en Historia de la transición en España: la dimensión internacional y otros estudios, ed. Mónica Amador Fernández (Madrid: Sílex, 2019), 311-331; Óscar J. Martín García y Francisco J. Rodríguez Jiménez, «The Engaging Power of English-Language Promotion in Franco's Spain», Contemporary European History 24/3 (2015): 415-435.

42 Rosa Pardo Sanz, «Las relaciones hispano-norteamericanas durante la presidencia de L.B. Johnson: 1964-1968», Studia historica. Historia contemporánea 22 (2004): 137-183, y «EE. UU. y el tardofranquismo: las relaciones bilaterales durante la presidencia Nixon», Historia del Presente 6 (2005): 11-42.

43 «Villar Palasí a Castiella», 4-marzo-1969 y «Castiella a Villar Palasí», 8 y 18-marzo-1969. Archivo General de la Administración, Ministerio de Asuntos Exteriores y Cooperación (AGA-MAEC), R-12190/6. 
El embajador español en Washington comunicó al Assistant Secretary of State norteamericano la pretensión de integrar en las negociaciones un programa vinculado a la reforma educativa. ${ }^{44}$

Inicialmente, el Ministerio de Asuntos Exteriores español (MAE) planteó a sus interlocutores americanos el posible establecimiento de un Comité conjunto para impulsar una mayor cooperación educativa y científica. En el ámbito de la enseñanza, Díez Hochleitner confeccionó un memorándum que contemplaba la colaboración con Estados Unidos en un punto clave de la reforma: la formación del profesorado. Una parte de la misma se preveía realizar en el extranjero y Estados Unidos se concebía como el principal punto de destino. El proyecto en cuestión preveía un lapso de duración de cinco años, con la idea de enviar allí cada año a 200 nuevos profesores a que mejorasen su formación en diversas especialidades junto a otros 150 profesores titulares y asociados para proceder a su reciclaje profesional, a lo que se agregaría el concurso norteamericano para instruir en España a otros 700 profesores más. ${ }^{45}$ El propio Díez Hochleitner viajó a Washington a mediados de 1969 para entrevistarse con representantes de la diplomacia americana, la United States Information Agency (USIA), el BM y las fundaciones Ford y Rockfeller. De esa forma se buscaba propagar las bondades de la reforma proyectada en España y explorar la apertura de espacios de cooperación y financiación.

La labor de persuasión ejercida por este y otros canales tuvo efectos positivos, como ya se ha mencionado en el caso de la Fundación Ford, y también entre los dirigentes americanos implicados en la materia. Aunque consideraron desmedido el volumen de las peticiones españolas, se mostraron bastante interesados en respaldar la reforma educativa, al considerar que ofrecía «una oportunidad excepcional para influir en las futuras generaciones de españoles y en la estructura global de la sociedad de una forma constructiva y acorde con nuestros intereses políticos a largo plazo». Además, el hecho de que, a su juicio, estuviese «ampliamente basada en modelos norteamericanos» suponía un acicate para

\footnotetext{
${ }_{44}$ Telegrama del Departamento de Estado, 17-marzo-1969. National Archives at College Park (NACP), RG 59, Subject Numeric File-Political and Defense (SNF) 1967-69, Spain, Box 1623.

45 «Spanish Base Negotiations. Position Paper: Establishment of Joint Scientific and Educational Committee» y «Spanish Request for US Aid to Spanish University Reform Program», 24-marzo-1969. NACP, RG 59, SNF 1967-69, Spain, Box 1624. «A Request to the Unites States Government for Assistance in the Training of Spanish Higher Education Professors». AGA-MAEC, R-9819/8.
} 
apoyarla. ${ }^{46}$ No en vano, algunos de los principales impulsores de los nuevos cambios educativos en España tenían una estrecha relación con el país americano, tal y como se detallaba en otro informe redactado por oficiales estadounidenses:

El grupo de expertos españoles encargados de la preparación de la ley está dirigido por un ex becario del programa de líderes extranjeros y Ministro de Educación, José Luis Villar Palasí. El principal arquitecto de la ley, el Subsecretario de Educación Ricardo Díez Hochleitner, es un antiguo estudiante de la Universidad de Columbia y experto en educación de la ONU. Muchos otros de sus colaboradores más importantes estudiaron o visitaron Estados Unidos con el auspicio del Gobierno norteamericano o de otras entidades privadas. ${ }^{47}$

Asimismo, los estadounidenses consideraban que la reforma educativa podría tener un efecto liberalizador sobre la cultura española, fomentar el acercamiento del país ibérico a sus vecinos europeos y mejorar la imagen pública de la alianza militar que mantenían con el régimen del general Francisco Franco desde 1953.48 La asistencia estadounidense a la modernización educativa del país permitiría mostrar el compromiso de la superpotencia con el progreso y el desarrollo de su aliado al sur de los Pirineos. Todos estos factores incidieron en la actitud favorable de los representantes estadounidenses, que mostraron su interés por explorar fórmulas que hiciesen factible su apoyo a la mencionada reforma. Los términos de esa cooperación fueron sondeados en sucesivas reuniones con representantes del MEC y del MAE durante los meses siguientes. ${ }^{49}$ Las negociaciones bilaterales llegaron a término, tras arduas negociaciones, en agosto de 1970, firmándose el Tratado de Amistad y Cooperación entre

\footnotetext{
46 «The Educational and Cultural Exchange Program with Spain», 27-octubre-1969. Bureau of Educational and Cultural Affairs-Historical Collection, University of Arkansas Libraries (BECA), Group IX, Box 240.

47 «Educational and Cultural Exchange: Annual Report for Spain for the Fiscal Year, July 1, 1969June 30, 1970», 23-septiembre-1970, BECA, Group XVI, Box 320.

48 «US Policy Assessment», 8-octubre-1969, "Annual US Policy Assessment», 21-noviembre-1970. NACP, RG 59, SNF 1967-69, Spain, Box 2493, y SNF 1970-73, Spain, Box 2599.

49 «Black Tie Dinner at the Spanish Embassy: Briefing Memorandum», 10-abril-1970. NACP, RG 59, SNF 1970-73, Spain, Box 2598. "Villar Palasí al Embajador en Washington», 3-marzo-1970. AGA-MAEC, R-9564/7.
} 
ambas naciones. Los representantes españoles no consiguieron satisfacer sus principales demandas en el terreno de la defensa y la seguridad, pero al menos lograron imprimir un mayor impulso y dinamismo en otras esferas bilaterales. El acuerdo incluyó varios programas de ayuda no militar -conocidos como Non-Military Agreements (NMA)- en los campos de la educación, la cultura, la ciencia, el medio ambiente, la economía, el desarrollo urbano y la agricultura. La cooperación cultural y educativa, junto con la científico-técnica constituyeron el núcleo de esos programas, comprometiéndose finalmente el gobierno estadounidense a aportar una ayuda de tres millones de dólares para ambos ámbitos. Una cantidad considerable, aunque sensiblemente menor a la solicitada por parte española. ${ }^{50}$

Una parte sustancial de dichos fondos fue dirigida a la financiación de proyectos vinculados a la reforma educativa contenida en la LGE. Entre dichas actividades destacó el programa de formación de gestores y administradores universitarios, cuya realización se encargó al Educational Technology Center del Sterling Institute de Washington. Poco después se inició otro programa con la Georgetown University para la enseñanza del inglés a profesores españoles de magisterio, que se complementaría con el envío a España de docentes norteamericanos especialistas en la materia. Por su parte, la National Science Foundation colaboró con el equipo del profesor Severo Ochoa en la creación del Instituto de Biología Molecular desde 1971. Con la puesta en marcha de este centro se pretendía avanzar en otro de los frentes de la LGE: fomentar la investigación en la universidad española y recuperar a algunos de los científicos más brillantes del país que habían desarrollado su carrera en el extranjero. La ayuda americana también se utilizó para la concesión de 264 becas de estudios para profesores e investigadores universitarios españoles en centros estadounidenses, sobre todo de especialidades de ciencias, con el propósito de fortalecer las «estructuras académicas, culturales y administrativas de la enseñanza superior, especialmente dentro de España».51 Simultáneamente, se

\footnotetext{
${ }^{50}$ Un análisis más en profundidad de la ayuda americana, su gestación y alcance, en Lorenzo Delgado Gómez-Escalonilla y Patricia de la Hoz, «US Assistance to Educational Reform in Spain: Soft Power in Exchange for Military Bases», en Teaching Modernization, ed. Martín and Delgado, 40-77.

51 «Informe del Programa de Cooperación Cultural entre España y los Estados Unidos de América», 4-noviembre-1976, y «Becas para españoles del Programa NMA». Archivo Comisión Fulbright-España (ACFE), Box 92/7.
} 
abrieron cauces de colaboración en otros ámbitos científico-técnicos (oceanografía, contaminación y medio ambiente, vivienda y desarrollo urbano, investigación agronómica, etc.), que acabaron cuajando con la asignación de mayores recursos en un futuro inmediato..$^{52}$ Por último, el programa de intercambios de la Comisión Fulbright-España fue igualmente reorientado hacia parcelas relacionadas con la LGE, tal y como reflejaban las líneas prioritarias de su memoria anual de 1971: (1) la formación de profesores (especialmente de inglés, pero también de otras disciplinas como matemáticas, física, economía y sociología), (2) la asistencia a los ICEs en la aplicación de nuevas técnicas y metodologías, (3) el fomento de la investigación en los campos de la pedagogía y de la psicología y (4) el asesoramiento a la reorganización de los departamentos universitarios y a la reforma del currículum. ${ }^{53}$

El gobierno norteamericano fue, pues, uno de los principales valedores exteriores de la LGE. Sin embargo, en el contexto de la revuelta global estudiantil de 1968, una excesiva identificación de la reforma educativa con la política exterior estadounidense podía desencadenar efectos contraproducentes. Para reducir dicha asociación, la diplomacia del país americano utilizó su influencia para alentar el compromiso de las organizaciones internacionales, sobre todo en lo que concierne al BM. Estas entidades ofrecían un paraguas multilateral que les daba una mayor capacidad de maniobra en el mundo educativo de países como España, cuyas circunstancias políticas y sociales podían hacer que una intervención directa y unilateral de la superpotencia americana propiciase el rechazo de sectores como los profesores y estudiantes. ${ }^{54}$ Además, el asesoramiento educativo prestado por los organismos internacionales solía disfrutar de un amplio prestigio modernizador entre las elites tecnocráticas y otros sectores dirigentes de los países en vías de desarrollo. El

\footnotetext{
${ }_{52}$ Lorenzo Delgado Gómez-Escalonilla y Rosa Pardo Sanz, «Ayuda americana y política de investigación en las postrimerías del franquismo», en Ciencia en Transición. El lastre franquista ante el reto de la modernización, eds. Lorenzo Delgado Gómez-Escalonilla y Santiago López (Madrid: Sílex, 2019), 229-270.

${ }^{53}$ Lorenzo Delgado, «"After Franco, What?”. La diplomacia pública de Estados Unidos y la preparación del post-franquismo», Claves internacionales en la transición española, eds. Óscar J. Martín García y Manuel Ortiz Heras (Madrid: Los Libros de La Catarata, 2010), 121.

54 Óscar J. Martín García y Lorenzo Delgado Gómez-Escalonilla, «Educational Reform, Modernization, and Development: A Cold War Transnational Process», en Teaching Modernization, ed. Martín and Delgado, 11.
} 
aval de la comunidad internacional, siempre que fuese compatible con sus intereses políticos, les proporcionaba una legitimidad y reconocimiento que utilizaban para consolidar sus proyectos a nivel interno, ${ }^{55}$ tal y como se señaló líneas atrás para el caso del comité de expertos de la UNESCO. A este respecto, la reforma educativa en España aspiraba a «legitimar el orden social desde nuevas bases culturales». ${ }^{56}$

En este marco, el ascendiente estadounidense contribuyó a que el BM -presidido desde 1968 por Robert McNamara, antiguo secretario de Defensa bajo los mandatos de John F. Kennedy y Lyndon B. Johnson-57 sumase sus esfuerzos en favor de la LGE. A finales de ese año las autoridades españolas se dirigieron al Banco en busca de financiación para sus planes de reforma educativa. Con ese propósito se produjeron, hasta el verano de 1970, diversos contactos y negociaciones en los que jugó un papel central de nuevo la figura de Díez Hochleitner, quien como ya se expuso había ocupado previamente un puesto directivo en el BM. En julio de 1969, Díez Hochleitner fue el encargado de redactar el memorándum de petición por parte del gobierno español de un préstamo al BM para implementar la reforma educativa. También estuvo al frente de la delegación española que, a principios de 1970, mantuvo diversas reuniones con representantes de la institución financiera a fin de conseguir asistencia económica en el campo educativo. ${ }^{58}$ Poco después, en mayo de ese año, vio la luz un informe de evaluación realizado por una comisión del BM tras una visita a España cursada durante el otoño anterior. Dicho informe se mostró favorable a otorgar de tal ayuda.

La financiación aportada por el Banco sería utilizada para crear instituciones educativas y proveer los servicios necesarios para lanzar la primera fase de la reforma, la cual contribuiría a transformar el «complejo y rígido sistema actual, que tiende a perpetuar las desigualdades

\footnotetext{
55 Connie McNeely, «Prescribing National Education Policies: The Role of International Organizations», Comparative Education Review 39/4 (1995): 502.

${ }^{56}$ Félix Ortega, «Las ideologías de la reforma educativa de 1970», Revista de Educación n. ${ }^{\circ}$ ext. «La Ley General de Educación veinte años después» (1992): 43.

57 Patrick A. Sharma, Robert McNamara's Other War: The World Bank and International Development (Philadelphia: University of Pennsylvania Press, 2019).

58 David Corrales Morales, «Much Ado about Nothing? Lights and Shadows of the World Bank's Support of Spanish Aspirations to Educational Modernization (1968-1972)», en Teaching Modernization, ed. Martín and Delgado, 133-135.
} 
educativas, sociales y económicas, en un vehículo moderno, flexible y eficiente para el progreso económico y social». ${ }^{59}$ A finales de junio de 1970 el BM accedió a la concesión a España de una importante partida de ayuda económica, destinada a financiar un proyecto piloto que consistía en la construcción y equipamiento de 19 centros de Educación General Básica (EGB), 20 de Bachillerato Unificado Polivalente (BUP) y ocho ICEs, además de colaborar a la puesta en marcha del CENIDE mediante la contratación de asesores técnicos. El importe del crédito del BM ascendía a 12 millones de dólares sobre un total del coste previsto de 24 millones (el otro 50\% correría a cargo del gobierno español). ${ }^{60}$ Desde los medios oficiales españoles se ponía el acento no solo en esa importante dotación económica, sino también en el interés mostrado por el BM hacia una iniciativa que podía «servir de modelo a otros países con la misma problemática». ${ }^{61}$

No pasó mucho tiempo antes de que las autoridades españolas comenzaran a plantear la necesidad de recibir un segundo préstamo, ante las limitaciones económicas que ya a comienzos de 1971 eran patentes para la puesta en marcha de la LGE. El viaje a España de su presidente, McNamara, en abril de aquel año, allanó el camino para recibir el beneplácito de la institución en junio de 1972, tras más de un año de negociaciones. En este caso, los representantes del BM mostraron su intención de financiar principalmente proyectos de educación superior y formación profesional, en detrimento de la educación primaria. En una línea similar a la establecida por el gobierno estadounidense ante la previsible desaparición de Franco en un porvenir cercano, el BM dio prioridad a aquellos proyectos centrados en la formación del capital humano necesario para impulsar cambios en la estructura económica, política y social del país ibérico. ${ }^{62}$ La financiación otorgada por el BM en este segundo préstamo tenía como objetivo la construcción y equipamiento de 39 institutos de secundaria, 37 centros de

\footnotetext{
59 «Appraisal of an education Project in Spain», 22-mayo-1970. World Bank Archives (WBA), Education Projects Department.

${ }_{60}$ Corrales, «Much Ado about Nothing?», 135.

${ }_{61}$ «El Banco Mundial colabora en la reforma educativa española», Enseñanza Media (enero-junio 1970): CLXXIX.

62 David Corrales Morales, «Helping the implementation of the reform. Los préstamos del Banco Mundial y su impacto en la educación de la infancia española (1970-1972)», en El factor internacional en la modernización educativa, científica y militar de España, eds. Lorenzo Delgado Gómez-Escalonilla et al., (Alicante: Biblioteca Virtual Miguel de Cervantes, 2017), 207-210.
} 
formación profesional, una escuela de ingeniería agrícola en Palencia, una universidad politécnica en Barcelona y cuatro ICEs. Según un informe del BM, dicho proyecto tenía el propósito de «ayudar al gobierno a conseguir los objetivos de la reforma educativa», mediante la provisión de recursos que ampliasen la educación secundaria y potenciasen la formación técnica y profesional. ${ }^{63}$ Sin embargo, tanto el primero como el segundo préstamo no alcanzaron los resultados esperados y solo llegaron a materializarse parcialmente. Ambos sufrieron algunos de los problemas que también lastraron la aplicación de la propia LGE, como los obstáculos institucionales y burocráticos, la falta de preparación del personal, las limitaciones financieras, la mala coordinación interdepartamental y las tensiones y desavenencias políticas. ${ }^{64}$

\section{CONSIDERACIONES FINALES}

1970 fue declarado Año Internacional de la Educación. Con la aprobación de la LGE el régimen franquista intentaba mostrar su sintonía con los aires de renovación de la enseñanza procedentes del exterior. ${ }^{65} \mathrm{~A}$ tal objeto se montó una campaña de propaganda que acompañó el arranque de la reforma educativa y tuvo su punto culminante en la Exposición de Realizaciones y Construcciones Educativas (1968-69). ${ }^{66}$ En la misma línea proselitista se prodigó el ministro Villar Palasí en foros como la I Conferencia de Ministros de Ciencia europeos en París, la XXXII Conferencia Internacional de Educación en Ginebra, o la Conferencia de la UNESCO en Venecia. ${ }^{67}$ Se trataba, en definitiva, de exhibir la LGE como una manifestación del progreso que deparaba al país «el Estado de obras» impulsado por el tardo-franquismo. ${ }^{68}$

\footnotetext{
${ }_{63}$ «Appraisal of a second education project, Spain», 15-mayo-1972. WBA, Education Projects Department.

${ }^{64}$ Corrales, «Ciudadanos del mañana», 411-425.

65 «1970: Año Internacional de la Educación. Exposición de realizaciones y construcciones del Ministerio de Educación y Ciencia en el bienio 1968-1969", Revista de Educación 209 (1970): 49-52.

${ }_{66}$ Organizada ese mismo año por el MEC y presentada en el Palacio de Velázquez de los jardines del Retiro madrileño.

${ }^{67}$ «Proyección internacional de nuestra Ley. Interés en las reuniones de París, Ginebra y Venecia», Enseñanza Media (agosto-septiembre 1970): 1-10.

${ }^{68}$ Una expresión popularizada por quien fuera ministro de Obras Públicas en la etapa final del régimen franquista. Gonzalo Fernández de la Mora, El Estado de obras (Madrid: Doncel, 1976).
} 
Los promotores de la reforma educativa procuraron obtener el aval internacional, con el fin de presentarla bajo una dimensión innovadora y con el patrocinio de las principales instituciones mundiales de referencia, así como de recabar la máxima financiación posible. También eran conscientes de que con esa medida contribuían a remozar la imagen exterior e interior del sistema político que la había patrocinado. La UNESCO, el BM, el PNUD, la Fundación Ford y el gobierno de Estados Unidos, además de otros agentes exteriores con menor protagonismo, respaldaron con asistencia técnica y fondos económicos de diversa envergadura la LGE, desde el convencimiento de que coadyuvaría a la modernización del país y a su avance cultural y socioeconómico. Estos actores internacionales también veían en la LGE un instrumento para, sin presionar a la dictadura, preparar el terreno para una futura evolución política pacífica y estable hacia un sistema compatible con las democracias occidentales. El voluntarismo de dichas expectativas estaba condicionado por la necesidad de mantener buenas relaciones con un régimen que, a pesar su naturaleza política dictatorial, se mostraba acomodaticio y colaborador con los intereses del bloque occidental liderado por la potencia americana. Por ello, los expertos y dirigentes internacionales cooperaron con una reforma educativa que, aunque fue elaborada por técnicos eficientes y bien cualificados, formaba parte de un proyecto de relegitimación autoritaria en clave modernizadora.

En su concepción inicial, como no dejaron de reconocer incluso los críticos al régimen franquista, la LGE incorporaba elementos renovadores que suponían, al menos sobre el papel, la transformación de un sistema educativo tradicional, concebido para satisfacer las necesidades de una minoría privilegiada, en un sistema moderno que amparaba las oportunidades de movilidad social. Pero no es menos cierto que tanto su gestación como su implementación posterior quedaron reservadas a un conclave de técnicos experimentados, sin recabar la participación de los profesores ni someterla a debate público ¿Era viable una ley de ese calado en el convulso contexto del tardofranquismo, máxime sin ganarse la complicidad de los docentes? ${ }^{69}$ Desde los organismos internacionales se insistió sobre la necesidad de contar con ese respaldo, pero la "permeabilidad» de la LGE entre quienes debían aplicarla en las aulas fue escasa.

69 Juan Puchol, «El Libro Blanco, ¿un nuevo plan de desarrollo?», Cuadernos para el Diálogo, extra XVI (1969): 50. 
Además, el clima de radicalización estudiantil replicado con la intensificación de la represión gubernamental contribuyeron a su deslegitimación. Desde amplios sectores del mundo universitario y docente se destacó su identificación con el poder dictatorial y se desdeñaron sus potencialidades modernizadoras para el sistema educativo. Conforme fue pasando el tiempo se hizo más perceptible el desajuste entre la ley y la realidad sobre la que pretendía actuar, dando lugar a una deriva autoritaria en su ejecución.

El apoyo exterior a la reforma educativa se vio inmerso en tales contradicciones. La LGE culminó una trayectoria de cooperación con las organizaciones internacionales que se remontaba a los años sesenta, enfocada a consolidar el desarrollo económico y extender el progreso social según las pautas articuladas por la global architecture of education. Las aspiraciones de la reforma educativa se circunscribían para las autoridades españolas al marco escolar, sin incluir veleidades de democratización en su funcionamiento. Por un lado, se aspiraba a cambiar un sistema educativo ineficiente y poco apto para la educación de masas que precisaba el desarrollo económico del país, con unos sectores industrial y de servicios en expansión que requerían un mayor volumen de técnicos y mano de obra especializada. Por otro, se buscaba articular mecanismos de promoción social que atenuasen las protestas en ascenso de medios laborales y estudiantiles. Las organizaciones internacionales y los países que cooperaron con su asesoramiento y financiación iban más allá, al menos en el plano teórico. Consideraban que la reforma educativa contenía la simiente de una mayor apertura del país, al introducir pautas más participativas y contenidos innovadores en un sector tan esencial para el futuro inmediato como era la enseñanza. Tales planteamientos optimistas tendían a minimizar que la LGE procedía de un régimen político sometido a la erosión del tiempo y a la oposición en ascenso de movimientos sociales que se resistían a aceptar su pervivencia indefinida. Los promotores de la reforma educativa intentaron conjugar su proyecto de «cambio planificado» con el «rearme legitimador» del franquismo. La conexión exterior actuó como un comodín de ese proceso.

A la postre, la deficiente respuesta del régimen franquista a las demandas formativas hizo del sistema educativo «el catalizador de gran parte de los conflictos y anhelos que caracterizaban al conjunto de la 
sociedad [...], el espacio privilegiado de convergencia antagónica entre la emergente sociedad civil y el anquilosado poder político».$^{70}$ Dicha fricción fue especialmente palpable en los campus universitarios, donde las crecientes protestas contra el sistema educativo y político de la dictadura acabaron por afectar incluso a la imagen de la ayuda prestada por las organizaciones internacionales. Entre las críticas que recibió la LGE no faltó la denuncia de estar «ligada a los intereses del capitalismo occidental», ${ }^{71}$ interpretándose la asistencia exterior como una muestra más de la satelización del franquismo a los designios del imperialismo estadounidense. ${ }^{72}$ Una valoración que contenía algunos indicios de verosimilitud, pero de una manera fuertemente distorsionada.

\section{Nota sobre los autores}

Lorenzo Delgado Gómez-Escalonilla es investigador del Consejo Superior de Investigaciones Científicas. Realizó su formación post-doctoral en el Centre d'Histoire des Relations Internationales Contemporaines, Université de Paris I-Sorbonne. Fue seleccionado por el International Visitor Program de Estados Unidos. Sus investigaciones en los últimos años han versado fundamentalmente sobre las relaciones internacionales entre España, Estados Unidos y Francia; la diplomacia pública; las transferencias científicas y educativas, y la asistencia militar extranjera, con especial dedicación al período de la Guerra Fría. Entre sus contribuciones recientes: «The Deployment of U.S. Military Assistance to Franco's Spain: Limited Modernization and Strategic Dependence» (2021, en Cold War History); Teaching Modernization. Spanish and Latin American Educational Reform in the Cold War (2020); Ciencia en Transición. El lastre franquista ante el reto de la modernización (2019); «El factor exterior en la consolidación y desarrollo de la dictadura» (2018, en ¿Qué sabemos del Franquismo? Estudios para comprender la dictadura de Franco); La apertura internacional de España. Entre el franquismo y la democracia (1953-1986) (2016); y US Public Diplomacy and Democratization in Spain. Selling Democracy? (2015).

\footnotetext{
70 Ortega, «Las ideologías de la reforma»: 33.

71 Comín, «Educación 1938-70»: 350.

72 Manuel Vázquez Montalban, La penetración americana en España (Madrid: EDICUSA, 1974), 360-365.
} 
Óscar J. Martín García es actualmente investigador del Programa Ramón y Cajal en el Departamento de Historia, Teorías y Geografía Políticas de la Universidad Complutense de Madrid. Tras iniciar su carrera investigadora en el estudio de los movimientos sociales, a partir de 2009 comenzó a trabajar en el campo de la historia internacional y de las relaciones exteriores. Dentro de estas áreas de investigación, se ha especializado en el poder blando de Estados Unidos y Reino Unido, la diplomacia pública y la política exterior hacia las dictaduras ibéricas en la Guerra Fría. Sobre estos temas, ha sido autor de varios artículos en revistas internacionales revisadas por pares (Contemporary European History, Cold War History y Contemporary British History) y coeditado volúmenes en editoriales de prestigio como De Gruyter Oldenbourg y Berghahn Books. Es IP del proyecto «Modernización, desarrollo y democratización. El papel de las potencias europeas occidentales y de las organizaciones internacionales en el cambio político y social de España» (PGC2018-097159-B-I00) y miembro del proyecto europeo «Free your mind: Youth Activism in Southern Europe in times of Dictatorship» European Commission, EACEA).

\section{REFERENCIAS}

Betancourt Mejía, Gabriel. Documentos para la historia del planeamiento integral de la educación. Bogotá: Universidad Pedagógica Nacional, 1984.

Campo, Salustiano del. Cambios sociales y formas de vida. Barcelona: Ariel, 1968.

Cavalieri, Elena. España y el FMI: la integración de la economía española en el sistema monetario internacional, 1943-1959. Madrid: Banco de España, 2014.

Comín, Alfonso C. «Educación 1938-70. De la ideología espiritualista a la ideología tecnocrática». Cuadernos para el Diálogo extra XXXVII (1973): 346352.

Corrales Morales, David. «Helping the implementation of the reform. Los préstamos del Banco Mundial y su impacto en la educación de la infancia española (1970-1972)». En El factor internacional en la modernización educativa, científica y militar de España, editado por Lorenzo Delgado Gómez-Escalonilla et al., 197-218. Alicante: Biblioteca Virtual Miguel de Cervantes, 2017.

Corrales Morales, David. "Ciudadanos del mañana»: La influencia estadounidense en la infancia durante el franquismo, 1953-75. PhD diss., Universidad Complutense de Madrid, 2019. 
Corrales Morales, David. «Much Ado about Nothing? Lights and Shadows of the World Bank's Support of Spanish Aspirations to Educational Modernization (1968-1972)». En Teaching Modernization. Spanish and Latin American Educational Reform in the Cold War, editado por Óscar Martín García y Lorenzo Delgado Gómez-Escalonilla, 127-148. New York: Berghahn Books, 2020.

De la Torre, Joseba y Mario García Zúñiga (eds.). Entre el mercado y el estado. Los planes de desarrollo durante el franquismo. Pamplona: Universidad Pública de Navarra, 2009.

Delgado Gómez-Escalonilla, Lorenzo. «El ingreso de España en la Organización Europea de Cooperación Económica», Arbor 669 (2001):147-179.

Delgado Gómez-Escalonilla, Lorenzo. «"After Franco, What?” La diplomacia pública de Estados Unidos y la preparación del post-franquismo». En Claves internacionales en la transición española, editado por Óscar J. Martín García y Manuel Ortiz Heras, 99-127. Madrid: Los Libros de La Catarata, 2010.

Delgado Gómez-Escalonilla, Lorenzo. «Educación para el desarrollo. OCDE, asistencia exterior y reforma de la enseñanza en la España del tardofranquismo», Foro de Educación 18/2 (2020): 127-148.

Delgado Gómez-Escalonilla, Lorenzo. «International Organizations and Educational Change in Spain during the Sixties». Encounters in Theory and History of Education 21 (2020): 70-91.

Delgado Gómez-Escalonilla, Lorenzo y Patricia de la Hoz, «US Assistance to Educational Reform in Spain: Soft Power in Exchange for Military Bases». En Teaching Modernization. Spanish and Latin American Educational Reform in the Cold War, editado por Óscar Martín García y Lorenzo Delgado Gómez-Escalonilla, 40-77. New York: Berghahn Books, 2020.

Delgado Gómez-Escalonilla, Lorenzo y Rosa Pardo Sanz. «Ayuda americana y política de investigación en las postrimerías del franquismo». En Ciencia en Transición. El lastre franquista ante el reto de la modernización, editado por Lorenzo Delgado Gómez-Escalonilla y Santiago López, 229-270. Madrid: Sílex, 2019. Díez Hochleitner, Ricardo. «La reforma educativa de la LGE de 1970. Datos para una crónica». Revista de Educación n. ${ }^{\circ}$ ext. "La Ley General de Educación veinte años después» (1992): 261-278.

Dorn, Charles y Kristen Ghodsee. "The Cold War Politicization of Literacy: Communism, UNESCO and the World Bank». Diplomatic History 36/2 (2012): 373-398.

Echeverría Zabalza, Javier. La movilidad social en España (1940-1991). Madrid: Itsmo, 1999.

Engerman, David. «The Romance of Economic Development and New Histories of the Cold War». Diplomatic History 28/2 (2004): 23-55.

Engerman, David et al. (eds.). Staging Growth: Modernization, Development and the Global Cold War. Boston: University of Massachusetts Press, 2003. 
Escolano Benito, Agustín. «Discurso ideológico, modernización técnica y pedagogía crítica durante el franquismo», Historia de la Educación 8 (1989): 7-27. Examen du developpment de l'enseignement dans les pays mediterranéens: Tendances et perspectives de l'enseignement dans les pays membres en voie de development. Paris: OECD, 1972.

Fernández de la Mora, Gonzalo. El Estado de obras. Madrid: Doncel, 1976.

Fernández Soria, Juan M. «Presentación. Influencias europeas en la política educativa española del siglo XX (presencias y ausencias, temas para la investigación histórico-educativa)». Historia de la Educación 24 (2005): 27-37.

Fiala, Robert y Audri Gordon Gordon. «Educational Ideology and the World Education Revolution, 1950-1970». Comparative Education Review 31/3 (1987): 315-333.

Formation et fonctions des techniciens. Espagne. Paris: OCDE, 1968.

González-Delgado, Mariano. "Estar a la altura de nuestro tiempo": la televisión educativa, la UNESCO y la modernización de la enseñanza en el franquismo», Hispania 265 (2020): 597-627.

González-Delgado, Mariano y Tamar Groves. «La enseñanza programada, la UNESCO y los intentos por modificar el currículum en la España desarrollista (1962-1974)», Espacio, Tiempo y Educación 4/2 (2017): 73-100.

González-Delgado, Mariano y Tamar Groves. «Educational Transfer and Local Actors: International Intervention in Spain during the Late Franco Period». En Teaching Modernization. Spanish and Latin American Educational Reform in the Cold War, editado por Óscar Martín García y Lorenzo Delgado Gómez-Escalonilla, 101-126. New York: Berghahn Books, 2020.

González-Delgado, Mariano y Tamar Groves. "UNESCO mediation in Francoist curriculum policy: The case of educational television in Spain». En Transnational Perspectives on Curriculum History, editado por Gary McCulloch, Ivor Goodson y Mariano González-Delgado, 83-107. London: Routledge, 2020.

Hernández Sandoica, Elena, Miguel A. Ruiz Carnicer y Marc Baldó Lacomba. Estudiantes contra Franco (1939-1975). Oposición política y movilización juvenil. Madrid: La Esfera de los Libros, 2007.

Jiménez Blanco, José. «Desarrollo económico-Democracia política». En España perspectiva 1972, 151-178. Madrid: Guadiana de Publicaciones, 1972.

Jones, Phillip W. Education, Poverty and the World Bank. New York: Sense Publishers, 2006.

La educación en España: Bases para una política educativa. Madrid: Ministerio de Educación y Ciencia, 1969.

La educación y el desarrollo económico-social: Planeamiento integral de la educación; Objetivos de España para 1970. Madrid: Ministerio de Educación Nacional, 1962. 
Las necesidades de educación y el desarrollo económico-social de España. Madrid: Ministerio de Educación Nacional-OCDE, 1963.

Las necesidades de graduados en España en el periodo 1964-1971 (Enseñanzas Media y Superior). Madrid: Dirección General de Promoción y Cooperación Científica, 1966.

Latham, Michel E. The Right Kind of Revolution: Modernization and US Foreign Policy from the Cold War to the Present. Ithaca, NY: Cornell University Press, 2012.

Lázaro Flores, Emilio. «Historia de las construcciones escolares en España». Revista de Educación 240 (1975): 114-126.

Martín García, Óscar. «La política exterior cultural del Reino Unido, el British Council y el final de la dictadura en España». En Historia de la transición en España: la dimensión internacional y otros estudios, editado por Mónica Amador Fernández, 311-331. Madrid: Sílex, 2019.

Martín García, Óscar y Lorenzo Delgado Gómez-Escalonilla (eds.). Teaching Modernization. Spanish and Latin American Educational Reform in the Cold War. New York: Berghahn Books, 2020.

Martín García, Óscar y Lorenzo Delgado Gómez-Escalonilla. «Educational Reform, Modernization and Development: A Cold War Transnational Process». En Teaching Modernization. Spanish and Latin American Educational Reform in the Cold War, editado por Óscar Martín García y Lorenzo Delgado Gómez-Escalonilla, 1-39. New York: Berghahn Books, 2020.

Martín García, Óscar y Francisco J. Rodríguez Jiménez. «¿Seducidos por el inglés? Diplomacia pública angloamericana y difusión de la lengua inglesa en España, 1959-1975». Historia y Política 29 (2013): 301-330.

Martín García, Óscar y Francisco J. Rodríguez Jiménez. «The Engaging Power of English-Language Promotion in Franco's Spain». Contemporary European History 24/3 (2015): 415-435.

Martínez Boom, Alberto. De la escuela expansiva a la escuela competitiva. Dos modos de modernización educativa en América Latina. Barcelona: Anthropos, 2004.

McNeely, Connie. «Prescribing National Education Policies: The Role of International Organizations». Comparative Education Review 39/4 (1995): 483-507.

Meyer, John W., Francisco Ramírez, Richard Robinson and John Boli-Bennet, «The World Educational Revolution, 1950-1970». En National Development and the World System: Educational, Economic, and Political Change, 19501970, editado por John W. Meyer y Michael T. Hannan, 37-56. Chicago: University of Chicago Press, 1979.

Milito Barone, Cecilia C. y Tamar Groves, «¿Modernización o democratización? La construcción de un nuevo sistema educativo entre el tardofranquismo y la democracia». Bordón 65/4 (2013): 135-148. 
Millán Barbany, Gregorio y Carlos Sánchez Tarifa. «Las enseñanzas técnicas en España». Anales de Moral Social y Económica (1964): 159-168.

Muns, Joaquim y Montserrat Millet. España y el Banco Mundial. Relaciones 1958-1994. Madrid: Mundi Prensa, 1994.

Ortega, Félix. «Las ideologías de la reforma educativa de 1970». Revista de Educación n. ${ }^{\circ}$ ext. «La Ley General de Educación veinte años después» (1992): 31-46.

Ossenbach, Gabriela, y Alberto Martínez Boom. «Itineraries of the Discourses on Development and Education in Spain and Latin America (circa 19501970)». Paedagogica Historica 47/5 (2011): 679-700.

Pardo Sanz, Rosa. «Las relaciones hispano-norteamericanas durante la presidencia de L.B. Johnson: 1964-1968». Studia historica. Historia contemporánea 22 (2004): 137-183.

Pardo Sanz, Rosa. «EE.UU. y el tardofranquismo: las relaciones bilaterales durante la presidencia Nixon». Historia del Presente 6 (2005): 11-42.

Principios de planeamiento. Washington: UNESCO, 1960.

Puchol, Juan. «El Libro Blanco, ¿un nuevo plan de desarrollo?». Cuadernos para el Diálogo, extra XVI (1969): 47-50.

Puelles Benítez, Manuel. «Tecnocracia y política en la reforma educativa de 1970». Revista de Educación n. ${ }^{\circ}$ ext. "La Ley General de Educación veinte años después» (1992): 13-29.

Rodríguez Jiménez, Francisco. «Forerunners of Change? The Ford Foundation's Activities in Francoist Spain». En Teaching Modernization. Spanish and Latin American Educational Reform in the Cold War, editado por Óscar Martín García y Lorenzo Delgado Gómez-Escalonilla, 78-100. New York: Berghahn Books, 2020.

Romero, José L. «Del Libro Blanco a la Ley General de Educación». En España Perspectiva 1971, 209-241. Madrid: Guadiana de Publicaciones, 1971.

Schriewer, Jürgen. «Sistema mundial y redes de interrelación: la internacionalización de la educación y el papel de la investigación comparada». Educación y Ciencia 1/15 (1997): 21-58.

Sharma, Patrick A. Robert McNamara's Other War: The World Bank and International Development. Philadelphia: University of Pennsylvania Press, 2019.

The Mediterranean Regional Project. Spain. Paris: OECD, 1965.

«The Mediterranean Regional Project». The OECD Observer 8 (1964): 1-12.

Vázquez Montalban, Manuel. La penetración americana en España. Madrid: EDICUSA, 1974.

Viñao, Antonio. Escuela para todos: Educación y modernidad en la España del siglo XX. Madrid: Marcial Pons, 2004. 